\title{
Faktor-Faktor Yang Mempengaruhi Interaksi Sosial Pada Anak Usia Dini: Literatur Review
}

\author{
Factors Affecting Social Interaction In Early Childhood : A Literature \\ Review
}

\author{
Batinah $^{1}$, Arum Meiranny², Atika Zahria Arisanti ${ }^{3}$ \\ Program Studi Sarjana dan Pendidikan Profesi Bidan Fakultas Kedokteran \\ Universitas Islam Sultan Agung Semarang \\ 1,2,3Email: batinahmahsun@gmail.com
}

\begin{abstract}
ABSTRAK
Salah satu bentuk perkembanganan usia dini adalah kemampuan berinteraksi sosial, perkembangan sosial dapat dipengaruhi bila kemampuan pengambilan peran sosial yang dilakukan anak sehingga menghasilkan anak mampu berpikir, serta mengerti cara bersikap kepada orang disekitar,. gambaran diri yang baik atau buruk anak dapat terpengaruh saat mereka berhasil atau tidak dalam bergaul. Anak mampu menyesuaikan dirinya terhadap lingkungan, menerima lingkungan dan pengalaman dalam hal positif lain selama melakukan kegiatan sosial merupakan modal dasar yang sangat penting. Literatur review ini bertujuan untuk menelaah terkait faktor apa saja yang dapat mempengaruhi interaksi sosial pada anak usia dini. Metode yang digunakan ialah tinjauan literatur review yang terdapat dalam database jurnal kesehatan yaitu Google Scholar dan Pubmed, artikel yang terpilih berdasarkan full text, free open acces, berbahasa inggris dan berbahasa indonesia. Penulisan literatur melalui database penulis menemukan 16 artikel melalui Google Scholar dan 4 artikel melalui PubMed. Setelah dilakukan telaah maka ada 8 jurnal yang sesuai. Hasil yang didapatkan ialah faktor yang mempengaruhi kemampuan berinteraksi pada anak ialah: pola asuh orang tua, lingkungan, bermain dengan teman sebaya dan penggunaan gadget.
\end{abstract}

Kata kunci: Faktor pengaruh interaksi, Kemampuan Interaksi sosial, Anak usia dini.

\section{ABSTRACT}

One form of early adolescence development is the ability to have interaction socially, social development can be affected if the kid's potential to take social roles makes children aware of the mind, feelings, and attitudes of others. the kid's high-quality or terrible self-image is encouraged if the kid is a success or not inside the affiliation. the kid's capacity to conform to the environment, acceptance of the surroundings and other high-quality reviews for the duration of social sports is a completely vital fundamental capital. Literature review aims to look at the related factors that have an effect on social interplay in early adolescence. In writing this newsletter, the method used was a overview of literature opinions contained in the database of health journals, particularly Google student and Pubmed, selected articles primarily based on complete textual content, unfastened open get admission to, in English and in Indonesian. Writing literature through the writer's database determined 16 articles thru Google student and four articles via PubMed. After the assessment was performed, there were 8 appropriate journals. The effects acquired were factors that have an effect on the capacity of interaction in kids, particularly: parenting, environment, gambling with friends and the usage of devices.

Keywords: Interaction influence factors, Social interaction ability, Early childhood.

\section{PENDAHULUAN}

Anak usia dini merupakan anak yang pada masa pertumbuhan serta perkembangan, baik di aspek fisik, kognitif, sosial emosional, kreativitas, bahasa dan komunikasi yang spesifik sesuai dengan tahap yang sedang dilewati oleh anak dari usia 0-6 Tahun 
(Kurnia, 2020). Pada masa ini akan menuntut banyak stimulasi perkembangan sehingga bisa mencapai titik yang optimal (Miranti and Putri, 2021).

Interaksi sosial merupakan hubungan antar invidu, individu dengan kelompok, dan kelompok antar kelompok. Interaksi sosial dapat terjadi bila adanya hubungan sosial serta apabila ada komunikasi yang terjadi berupa langsung maupun dengan melalui perantara (tidak langsung), oleh karena itu interaksi sosial menjadi acuan dari semua bentuk kehidupan sosial. (Viandari and Susilawati, 2019). Interaksi sosial juga salah satu bentuk perkembangan yang terjadi pada anak. Hubungan sosial anak bisa dipengaruhi oleh kemampuan pengambilan peran sosial yang ada sebagai akibatnya anak akan memahami pemikiran terhadap dirinya, serta sikap terhadap orang lain. Gambaran diri anak baik pada hal positif maupun negatif dipengaruhi oleh keberhasilan anak dalam bersosialisasi, ketika bersosialisasi anak bisa beradaptasi dengan lingkungannya, dan pengalaman selama melakukan kegiatan sosial merupakan modal dasar yang sangat penting buat kehidupan anak yang membuat mereka merasa senang di masa yang akan tiba (Latifah and Sagala, 2015).

Kemampuan interaksi sosial sangat penting pada anak usia dini sebab dalam berinteraksi anak akan diajarkan cara hidup bermasyarakat di lingkungannya, kemudian anak akan dibimbing berbagai macam peran sebagai indentifikasi dalam dirinya, selain itu saat berinteraksi sosial anak mendapatkan banyak sekali berita yang ada disekitarnya. saat anak merasa nyaman saat beradaptasi dengan teman seusia dan lingkungannya maka perkembangan sosialnya menjadi optimal (Nur Asiah, Ari Sofia, 2019).

Pertumbuhan dan perkembangan yang terjadi pada anak tidak terlepas dari usaha orang tua beserta keluarga. Orang tua dan orang-orang terdekat dapat memberikan pengaruh besar terhadap pertumbuhan dan perkembangan sebab mereka menjadi rumah pembelajaran yang pertama yang dapat dijadikan contoh.

Penelitian yang dilakukan (Irma dkk, 2019) dalam penelitiannya didapatkan bahwa orang tua berperan sebagai manajerial dalam perkembangan sosial emosional anak, orang tua dapat memberikan peluang agar anak menjalin hubungan bersosial bersama 
teman seusianya maupun orang dewasa. Bagian penting lainnya dari kedudukan orang tua sebagai pengawas anak adalah pemantauan secara efektif yang meliputi memilih lingkungan yang tepat agar bisa dijadikan tempat bersosialisasi yang baik sehingga perkembangan anak dapat dipantau dengan efektif (Irma et al., 2019).

Penelitian yang telah dilakukan (Adhani, Eater and Dini, 2019) juga didapatkan bahwa perkembangan interaksi sosial anak dilihat dari nature dan nurture yang bisa membuat perkembangannya men-jadi optimal. Tugas orang tua sangat penting dalam masa perkembangan anak, dalam kehidupan anak tidak hanya memberikan dan mencukupi kebutuhan anak secara materi, namun orang tua juga harus ikut terlibat secara aktif untuk pertumbuhan dan perkembangan anak. Orang tua juga bertugas untuk menambah wawasan anak dengan cara memasukkan anak kesekolah, mendampingi anak ketika sedang belajar, membantu anak saat susah memahami pelajaran, memberik-an motivasi, saat belajar memberikan suasana yang disenangi, memberikan perhatian serta kasih sayang dan menanamkan budi pekerti yang baik
(Adhani, Eater and Dini, 2019). Saat mendidik anak orang tua akan mendidik dengan berbeda-beda yang disebabkan karena adanya perbedaan latar belakang pendidikan, budaya, ekonomi dan sosial, sehingga hal ini dapat menentukan keberhasilan tugas serta keterlibatan dalam meningkatkan pendidikan anak saat berinteraksi sosial (Twistiandayani and Umah, 2017).

Tujuan dari studi literatur review ini yaitu menelaah lebih dalam lagi terkait faktor apa saja yang dapat mempengaruhi kemampuan interaksi sosial pada anak di usia dini, berdasarkan beberapa hasil penelitian yang telah dilakukan sebelumnya dengan cara mereview beberapa artikel penelitian.

\section{METODE PENELITIAN}

Penulisan artikel ini dilakukan dengan menggunakan metode Literature Review yang menggunakan referensi dari jurnal dan artikel mengenai faktor-faktor yang dapat mempengaruhi interaksi sosial pada anak usia dini. Artikel-artikel diperoleh melalui database Google Scholar dan PubMed. Kriteria inklusi dan seleksi dokumen dengan menggunakan kata kunci yaitu "Faktor yang mempengaruhi interaksi sosial anak 
usia dini" atau "social interaction skill on children". Penulisan literatur melalui database penulis menemukan 16 artikel melalui Google Scholar dan 4 artikel melalui PubMed. Setelah dilakukan telaah maka ada 8 jurnal yang sesuai untuk dijadikan acuan dalam penelitian ini yang terdiri dari 5 jurnal Nasional dan 3 jurnal Internasional.

\section{HASIL DAN PEMBAHASAN}

Keterampilan dalam berinteraksi sosial yang berupa kemampuan saat berkomunikasi, berkerjasama, berpartisipasi, berbagi, dan beradaptasi (dalam bentuk simpati, empati) maupun memecahkan suatu masalah dan disiplin sesuai dengan aturan yang berlaku. Anak yang memiliki kesadaran diri yang tangguh serta kuat membuat mereka siap saat menjalani hidup bersama dengan orang lain (Mushfi, 2017).

Menurut (Halid dalam Munisa 2020) faktor yang dapat mempengaruhi interaksi sosial anak, antara lain : peran orang tua saat memberikan asuhan kepada anaknya, lingkungan, hubungan antar teman sebaya (Munisa, 2020), serta penggunaan gadget juga salah satu faktor yang dapat mempengaruhi interaksi sosial pada anak (Nur Asiah, Ari Sofia, 2019).

a. Pola Asuh orang tua

Pola asuh orang tua termasuk salah satu faktor yang bisa menambah perkembangan ataupun penghambat tumbuhnya kreati-vitas pada anak. Anak yang terbiasa dengan kebiasaan dalam keluarga yang saling menghargai, menerima perbedaan pendapat anggota keluarga, sehingga ia akan tumbuh menjadi generasi terbuka, penuh dengan inisiatif yang baik, produktif, suka akan tantangan serta percaya diri (Robbiyah, Ekasari and Witarsa, 2018).

Proses bimbingan yang diberikan orang tua dapat mempengaruhi perkembangan anak dalam mengenal berbagai aspek kehidupan sosial, atau aturan saat berada di kehidupan bermasyarakat serta memberikan motivasi dan contoh kepada anak bagaimana menerapkan atursan tersebut dalam kehidupan seharihari. Penelitian yang dilakukan (Robbiyah, Ekasari and Witarsa, 2018) bahwa kemampuan dalam meningkatkan hubungan sosial 
juga sangat dipengaruhi oleh didikan yang diberikan ibu/orang tua, keber-hasilan seorang ibu mendidik anak akan terlihat apabila seberapa besar keikut sertaan ibu dalam mengawasi kehidupan anak. Cara mendidik yang diterapkan ibu yaitu dengan cara demokratis, dengan cara tersebut dapat meningkatkan kemampuan anak saat interaksi sosial dengan lingkungannya.

b. Lingkungan

$$
\begin{aligned}
& \text { Penciptaan lingkungan } \\
& \text { belajar dapat memfasilitasi } \\
& \text { multisensori anak seperti } \\
& \text { menyiapkan dan mengelola } \\
& \text { lingkungan belajar yang dapat } \\
& \text { merangsang berbagai indra anak } \\
& \text { secara baik. Dalam pembelajaran } \\
& \text { hendaknya anak dibimbing untuk } \\
& \text { mengendalikan dirinya sendiri } \\
& \text { secara baik. Lingkungan juga } \\
& \text { dapat sebagai wadah bagi anak } \\
& \text { untuk ikut serta bergaul di luar } \\
& \text { rumah, disana anak dapat } \\
& \text { menemukan orang lebih banyak, } \\
& \text { seperti teman sebaya, usia lebih } \\
& \text { kecil darinya, orang dewasa, } \\
& \text { sehinggga terjadi peningkatan } \\
& \text { dalam interaksi sosialnya kemu- } \\
& \text { dian peran di lingkungannya juga }
\end{aligned}
$$

dapat berjalan dengan lancar

(Munisa, 2020).

Penelitian yang dilakukan (Ismiatun, 2020) juga didapatkan hasil bahwa lingkungan tempat tinggal berpengaruh pada perkembangan kognitif sosial anak karena dapat diketahui bahwa perbedaan lingkungan tempat tinggal mempengaruhi perkembangan sosial anak, namun tidak secara dominan atau signifikan.

c. Hubungan antar Teman Sebaya

Anak yang memasuki masa perkembangan dalam hal differ-ensiasi, dimana pada masa tersebut anak telah mengerti dan memahami orang lain. Maka anak sudah tidak lagi melihat segala sesuatu hanya untuk dirinya sendiri melainkan ia juga akan memikirkan temannya. Anak akan memulai untuk memahami dirinya sendiri, kemudian memahami teman bermainnya. Hal tersebut bertujuan agar lebih mudah mendekatkan diri dengan teman yang menjadi wadah dalam mempersatukan pemikiran dan tingkah laku dirinya kepada teman seusianya. Sehingga munculnya rasa percaya antar teman yang 
membuat terjadinya aktivitas

hubungan sosial serta terjalin

keakraban satu sama lain.(Munisa, 2020).

Bermain dengan teman sebaya juga menjadi salah satu faktor yang dapat mempengaruhi interaksi sosial pada anak, hal ini sesuai dengan hasil penelitian yang dilakukan (Nurhayati, Melwani and Ida, 2020) dalam penelitiannya didapatkan hasil bahwa dengan bermain anak akan meningkatkan pengembangan interaksi sosial karena saat bermain akan mengalami semangat yang tinggi, dapat mengekspresikan diri, meningkatkan kepercayaan pada diri dan dapat melatih kemampuan bersosialisasi yang membentuk sikap empati dan simpati. Sejalan dengan penelitian (Rahmadianti, 2020) bahwa bermain merupakan kebutuhan anak, karena dapat meningkatkan perkembangan sosial dan pengetahuan yang baru bagi anak.

d. Penggunaan Gadget

Saat ini gadget semakin berkembang menjadi sebuah barang yang sangat menarik sehingga memudahkan pengguna, kemudian sudah dilengkapi dengan berbagai bentuk aplikasi diantaranya seperti aplikasi permainan yang saat ini sudah berkembang sangat bervariasi, permainan bertemakan peperangan sampai pembelajaran. Penyajian setiap aplikasi yang beraneka macam bentuk dan karakter tidak heran apabila anakanak sangat senang saat bermain gadget (Marsal et al., 2017).

Penelitian dilakukan oleh (Suhana, 2018) menjelaskan bahwa dampak penggunaan gadget pada anak juga dapat menyebabkan kurangnya interaksi serta komunikasi, anak menjadi tak percaya diri, pendiam, lebih senang menyendiri serta tidak sabaran, lalu timbulnya persoalan kurangnya keterampilan komunikasi interpersonal dan menjauhkan mereka dari lingkungan sekitarnya. Sejalan dengan hasil penelitian yang telah dilakukan (Ariston \& Frahasini,2018) bahwa pemakaian gadget pada anak akan memberikan resiko terhadap hubungan sosialnya sebab anak akan cenderung individualis, lebih asik menggu-nakan gadget, susah 
bergaul sehingga bila sudah ketergantungan akan sulit buat dikontrol dan pada akhirnya otak anak juga sulit buat berkembang sebab hari-harinya digunakan untuk selalu bermain game.

Penelitian yang dilakukan (Maulida et al., 2020) juga mengungkapkan bahwa anak yg ketergantungan bermain game online dalam jangka waktu yang lama tanpa adanya pengawasan dari orang tua maka hubungan sosial yang akan dilakukan seharihari juga akan menurun hal ini terjadi karena anak telah merasa asik sendiri dengan bermain gadget dan merasa tidak perlu bermain dengan teman sebayanya (Anggraeni, 2019).

Penelitian yang telah dilakukan oleh (Miranti and Putri, 2021) dimana pada penelitian menun-jukkan bahwa gadget memiliki pengaruh yang besar dengan kemampuan bersosial anak pada masa usia dini. Penggunaan gadget yang berlebihan akan membawa dampak buruk bagi hubungan sosial dan emosional anak. Akibat lain dari pemakaian gadget pada anak diantaranya anak menjadi pribadi yang misterius, pola tidur terganggu, lebih senang menyendiri, berperilaku keras, kemudia akan menyebabkan hilangnya kreativitas pada anak dan ancaman terjadinya cyberbullying.

\section{SIMPULAN DAN SARAN}

Sesuai literature review yang telah dilakukan penulis, maka dapat ditarik suatu kesimpulan bahwa kemampuan berinteraksi sosial sangat penting bagi anak usia dini, karena dengan berinteraksi anak menjadi lebih praktis mengenal lingkungan sekitarnya. Terdapat beberapa faktor yang mempengaruhi kemampuan dalam berinteraksi pada anak yaitu: pola asuh orang tua, lingkungan hubungan antar teman seusia, dan penggunaan gadget yang tidak terkontrol. Sebagai orang tua selalu ajarkan anak untuk mengenal lingkungannya dengan baik, mengajak anak bermain bersama teman-teman seusianya dan membatasi memberikan gadget pada anak supaya kemampuan interaksi sosial anak semakin baik dimasa mendatang. 


\section{DAFTAR PUSTAKA}

Adhani, D. N., Eater, P. and Dini, A. U. (2019) 'Peran Orang Tua terhadap anak usia dini ( usia 2 tahun ) yang mengalami Picky Eater', Journal on Early Childhoodhildhood, 2(1), pp. 39-44.

Anggraeni, S. (2019) 'Pengaruh Pengetahuan Tentang Dampak Gadget Pada Kesehatan Terhadap Perilaku Penggunaan Gadget Pada Siswa SDN Kebun Bunga 6 Banjarmasin', Faletehan Health Journal, 6(2), pp. 64-68. doi: 10.33746/fhj.v6i2.68.

Ariston, Y. and Frahasini, F. (2018) 'Dampak Penggunaan Gadget Bagi Perkembangan Sosial Anak Sekolah Dasar', Journal of Educational Review and Research, 1(2), p. 86. doi: 10.26737/jerr.v1i2.1675.

Irma, C. N. et al. (2019) 'Jurnal Obsesi : Jurnal Pendidikan Anak Usia Dini Keterlibatan Orang Tua dalam Pendidikan Anak Usia Dini di TK Masyithoh 1 Purworejo', Jurnal Obsesi : Jurnal Pendidikan Anak Usia Dini, 3(1), pp. 214-224. doi: 10.31004/obsesi.v3i1.152.

Ismiatun, A. (2020) Studi Komparatif Perkembangan Sosial Anak Usia 5-6 Didesa Dan Kota', jurnal tunas siliwangi, 6(2), pp. 8-12.

Kurnia, L. (2020) 'Dampak Interaksi Sosial Anak Usia Dini Akibat Latar Belakang Orangtua Tuna
Wicara', jurnal PIAUD La Tansa, 1(1), pp. 1-16.

Latifah, U. and Sagala, A. C. D. (2015) 'Upaya Meningkatkan Interaksi Sosial Melalui Permainan Tradisional Jamuran Pada Anak Kelompok B Tk Kuncup Sari Semarang Tahun Pelajaran 2014/2015', Penelitian PAUDIA, pp. 112-132.

Marsal, A. et al. (2017) 'Pengaruh Smartphon Dengan Interaksi Sosial', jurnal ilmiyah rekayasa dan manajemen sistem informasi, 3(1), pp. 78-84.

Maulida et al. (2020) 'Pengaruh Intensitas Bermain Game Online Terhadap Interaksi Sosial Remaja', Journal of Chemical Information and Modeling, 53(9), p. 287.

Miranti, P. and Putri, L. D. (2021) 'Waspadai dampak penggunaan gadget terhadap perkembangan sosial anak usia dini', Jendela PLS, 6(1), pp. 58-66. Available at:

http://jurnal.unsil.ac.id/index.ph p/jpls/article/view/3205.

Munisa (2020) 'Pengaruh Penggunaan Gadget Terhadap Interaksi Sosial Anak Usia Dini Di TK Panca Budi Medan', Jurnal Abdi Ilmu, 13(1979-5408), pp. 102114.

Mushfi, M. (2017) 'Model Interaksi Sosial Dalam Mengelaborasi Keterampilan Sosial', jurnal pedagogik, 04(02), pp. 211-227.

Nur Asiah, Ari Sofia, S. (2019) 'Hubungan Penggunaan Gadget 
terhadap Interaksi Sosial Anak Usia 5-6 Tahun', Persepsi Masyarakat Terhadap Perawatan Ortodontik Yang Dilakukan Oleh Pihak Non Profesional, 53(9), pp. 1689-1699.

Nurhayati, S., Melwani, M. P. and Ida, W. W. (2020) 'Perkembangan Interaksi Sosial Dalam Meningkatkan Kemampuan Sosial Emosional Melalui Permainan Congklak Pada Anak Usia 5-6 Tahun', Jurnal Buah Hati, 7(2), pp. 125-137.

Rahmadianti, N. (2020) 'Pemahaman Orang Tua Mengenai Urgensi Bermain Dalam Meningkatkan Perkembangan Sosial Anak Usia Dini', Jurnal Pendidikan : Early Childhood, 4(1), pp. 57-64.

Robbiyah, R., Ekasari, D. and Witarsa, R. (2018) 'Pengaruh Pola Asuh Ibu terhadap Kecerdasan Sosial Anak Usia Dini di TK Kenanga Kabupaten Bandung Barat',
Jurnal Obsesi : Jurnal Pendidikan Anak Usia Dini, 2(1), p. 74 . doi: 10.31004/obsesi.v2i1.10.

Suhana, M. (2018) 'Influence of Gadget Usage on Children's SocialEmotional Development', 169(Icece 2017), pp. 224-227. doi: 10.2991/icece-17.2018.58.

Twistiandayani, R. and Umah, K. (2017) 'Faktor-Faktor Yang Mempengaruhi Interaksi Sosial Pada Anak Autis', Prosiding SNaPP: Kesehatan (Kedokteran, Kebidanan, Keperawatan, Farmasi, Psikologi), 3(1), pp. 23-30.

Viandari, K. D. and Susilawati, K. P. A. (2019) 'Peran pola asuh orangtua dan penggunaan gadget terhadap interaksi sosial anak prasekolah', Jurnal Psikologi Udayana, 6(01), p. 76. doi: 10.24843/jpu.2019.v06.i01.p08. 